\title{
Pulsed Electron Beam Treatment of MCrAIY Bondcoats for EB PVD TBC Systems Part 2 of 2: Cyclic oxidation of the coatings
}

\author{
R. G. Wellman ${ }^{1}$, A. Scrivani ${ }^{2}$, G Rizzi ${ }^{2}$, A Weisenburger ${ }^{3}$, F.H. Tenailleau ${ }^{1}$ and J. R. \\ Nicholls ${ }^{1}$ \\ ${ }^{1}$ Cranfield University, College Rd Cranfield, MK43 OAL, UK \\ ${ }^{2}$ Turbocoating, Italy. \\ ${ }^{3}$ Forschungszentrum Karlsruhe GmbH, IHM, O.O. Box 3640, 76021 Karlsruhe, Germany.
}

\begin{abstract}
This paper discusses the effect of pulsed electron beam (PEB) treatment of thermal sprayed MCrAlY bondcoats on the cyclic life of thermal barrier coatings (TBCs). Standard MCrAlY bondcoats were produced via HVOF, VPS and LPPS thermal spray methods. Some of the HVOF and VPS coatings were then given a PEB treatment before all the samples were coated with an EB PVD 7-8wt\% yttria partially stabilized zirconia topcoat. The samples were all tested under cyclic oxidation conditions at $1150^{\circ} \mathrm{C}$ with $1 \mathrm{hr}$ at temperature and $15 \mathrm{~min}$ cooling, samples were removed after $20 \%$ coating spallation and prepared for cross sectional analyses.
\end{abstract}

Cyclic testing revealed that although the PEB treatment had no measurable effect on the VPS sprayed samples, the HVOF coatings showed a significant increase in the cyclic life after the PEB treatment. The effect of the PEB treatment on the various samples is discussed as well as its effect on TGO growth morphology. PEB treatment of the HVOF bondcoat was found to reduce the rate of alumina growth and to suppress the formation of oxide pegs resulting in a smoother bondcoat interface. 


\section{Introduction}

Thermal barrier coatings in various forms have been in commercial use for a number of decades $[1,2]$ with oxidation recognized as the primary cause of failure [3-5] and erosion as a secondary cause of failure [6,7]. A significant amount of research has been conducted over the years on the oxidation behavior of TBCs often focusing on the growth and morphology of the thermally grown oxide (TGO) [8]. Ideally the aim is to obtain a continuous alpha alumina oxide that is slow growing and to minimize the rate of internal oxidation of the bond coat.

The aim of the project was to determine the effect of pulsed electron beam (PEB) re-melting treatment on the cyclic oxidation life of EB PVD TBCs with MCrAlY bondcoats. This paper is part two of two papers where paper one [9] discusses the production of the coatings and the PEB treatment in greater detail. Various TBCs have been used in gas turbine engines for a number of decades, however, oxidation of the bondcoat is the primary cause of failure of TBCs, with erosion often reported as the secondary cause of failure. The thermally grown oxide (TGO), ideally a continuous alpha alumina scale, grows throughout the life of the TBC. This growth introduces stresses into the TBC system which eventually results in spallation of the TBC.

\section{Sample Production}

The samples were produced by a consortium. The MCrAlY bond coats, the composition of which is given in Table 1, were sprayed by Turbocoating and the PEB treatment was done by Forschungszentrum Karlsruhe. Finally an $8 \mathrm{wt} \%$ yttria stabilized zirconia top coat was applied by EB PVD at Cranfield University, who also produced the PtAl diffusion bond coat. 
Inconel 738, a nickel based superalloy often used for the production of gas turbine blades and vanes, was used as the substrate for the samples with the sprayed bond coats, which were $3 \mathrm{~cm}$ squares $5 \mathrm{~mm}$ thick. Before the deposition of the MCrAlY bond coat, the substrates were grit blasted using corundum with a grain size of $60-80$ mesh, in order to remove surface oxide and grease and to obtain a suitable roughness for coating adhesion.

CoNiCrAlY commercial powder was used, with a nominal chemical composition equivalent to the powder known as AMDRY 995, again widely used for coating gas turbine components. The grain size distribution of the powder was different according to the process used for the deposition. Coating thickness varied in the range $100-150 \mu \mathrm{m}$. After coating, the samples were heat treated in vacuum at $1100{ }^{\circ} \mathrm{C}$ for $2 \mathrm{~h}$ to obtain metallurgical bonding between the base material and the coating. Three different processes were used for depositing the sprayed bond coats, Vacuum Plasma Spray (VPS), Low Pressure Plasma Spray (LPPS) and High Velocity Oxygen Fuel (HVOF). After diffusion heat treatment some of the samples were given a pulsed electron beam (PEB) treatment to re-melt the top layer of the bond coat this is discussed in more detail in part 1 [9].

The PtAl bond coats were produced at Cranfield University by sputter coating a $7 \mu \mathrm{m}$ Pt layer onto $20 \mathrm{~mm}$ diameter $5 \mathrm{~mm}$ thick CMSX-4 buttons. The Pt was then diffused into the substrate in a vacuum for $2 \mathrm{hrs}$ at $1140^{\circ} \mathrm{C}$. After diffusion heat treatment, samples were aluminized in a CVD rig at Cranfield using an in pack high activity method for $25 \mathrm{~min}$. The samples were then given a recovery heat treatment of $2 \mathrm{hrs}$ at $1120^{\circ} \mathrm{C}$ followed by $24 \mathrm{hrs}$ at 843 in vacuum, before being prepared for deposition of the ceramic top coat. 
All of the samples were given a very light grit blast before the $8 \mathrm{wt} \%$ yttria stabilized zirconia top coat was applied to the finished bond coats in the EB PVD evaporator at Cranfield University. The thickness of the ceramic top coat applied to all the samples was $150-175 \mu \mathrm{m}$.

\section{Cyclic Testing}

The samples were tested in one of the Cranfield cyclic oxidation test rigs at $1150^{\circ} \mathrm{C}$ for $1 \mathrm{hr}$ $12 \mathrm{~min}$ cycles ( $1 \mathrm{hr}$ at temperature) with $15 \mathrm{~min}$ forced air cooling. The samples were all cycled continuously and examined on a regular basis throughout the day during the cooling cycle. When the samples were close to failure, they were examined more frequently. The samples were considered to have failed after $20 \%$ of the coating had spalled from the surface. After the $20 \%$ failure criterion was reached and the samples were removed from the furnace it was found that they were prone to desk top failure. A number of samples suffered from desk top failure within a few minutes of removal from the test rig resulting in significant loss of the ceramic topcoat.

\section{Results and Discussion}

The results of testing conducted to date are given in Table II. As can be seen from the table, the PEB treatment has no significant effect on the VPS bond coats however, initial results indicate a significant improvement in the life of the HVOF sprayed bond coats given the PEB treatment. Due to this apparent dramatic increase in life of the HVOF PEB treated samples, this paper will concentrate on the analyses of the HVOF sprayed samples with and without the PEB treatment. The SEM Micrographs in Figures 1 and 2 illustrate that there is a significant difference in the growth and morphology of the TGO between the HVOF sample and the PEB treated HVOF sample. 
The untreated HVOF sample shows typical failure characteristics of thermal barrier coatings with the formation of an alumina TGO which appears to have undergone extensive rumpling followed by the formation of breakaway oxides (Figure 1a). A high degree of internal oxidation was also observed in this sample. This behavior is very similar to that observed by Sohn et al[8] and illustrated schematically in Figure $1 b[8]$. On the other hand the HVOF sample with the PEB treatment shows a smooth continuous oxide layer (Figure 2).

Furthermore there is a significant difference in the oxide thickness of the samples at failure as shown in Figure 3. The oxide thickness measured for the HVOF sample is significantly higher than the sample with the PEB treatment even though the sample with the PEB treatment was at temperature for twice as long (for these particular samples). This difference in oxide thicknesses is attributed to the large areas of breakaway oxidation in the HVOF sample whereas the PEB treated HVOF bond coat had far fewer areas of breakaway oxidation and no evidence of peg formation was observed.

A consequence of the PEB re-melt layer is a significant improvement in the oxidation resistance, and consequently a significant increase in the life, of the PEB treated sample under cyclic oxidation conditions. This is clearly evident in the micrographs of cyclically oxidised samples that have part-spalled the ceramic topcoat. The HVOF samples had a mean lifetime of $410 \mathrm{~h}$, while the PEB treated HVOF sample had a mean lifetime of $850 \mathrm{~h}$ at $1150^{\circ} \mathrm{C}$.

Clearly, there is noticeable difference between the cyclic oxidation performance of the HVOF bond coat system. Without the PEB treatment the bond coat has a much thicker thermally grown oxide (TGO) and shows extensive internal oxidation, after 471 x $1 \mathrm{~h}$ cycles of oxidation as illustrated in Figure 1 (sample from test 1 in Table II). The TGO formed on the non PEB 
treated samples generally consisted of an outer alumina layer, over an inner region of oxide that was predominately chromia. Cracks are generated in this layer, as a result of thermal cycling, passing in a tortuous manner through the middle of this mixed oxide scale. Internal oxidation and nitridation are observed, with extensive oxides formed at prior particle boundaries and at porosity in the coating. Internal oxidation and nitridation depletes the coating alloy of scale forming elements and contributes to the early cyclic failure of this TBC coated, HVOF sprayed bondcoat.

On the other hand the PEB processed sample, shown in Figure 2, had a thermally grown oxide that was much more uniform and was purely alumina, with no evidence of chromia or nickel, cobalt spinel subscales. This more ideal structure, as illustrated in Figure, was observed after $921 \times 1 \mathrm{~h}$ hot cycles. Less internal oxidation was observed, but there was extensive nitride formation within the lower part of the MCrAlY bondcoat. These nitride phases have been analysed and were found to be AIN, with a small solubility of chromium. Such nitride phases were embryonic in the as-sprayed and PEB processed coating, which raises the question whether significant nitrogen is introduced into the MCrAlY bondcoat as part of the HVOF spray process, as it is unlikely that the nitrogen was transported through the alumina scale during oxidation.

The SEM micrograph in Figure 4 shows a region of breakaway oxidation in the HVOF PEB bond coat which has initiated cracking in the continuous alumina scale. This failure appears to be a type of jacking failure mechanism similar to that which has been described previously by other researchers [10-12]. Whereby, highly localised breakaway oxidation appears to jack up the coating in the region immediately above it as it grows. As the break away oxidation grows and the coating is jacked up, cracking will initiate at the TGO bond coat interface and as this crack propagates spallation of the top coat will occur. 
In order to verify some of the compositions of the various oxides that were observed in the two coating types, SEM EDX analyses were used. The SEM micrograph in Figure 5 shows where three point analyses were conducted on the HVOF sample, see Table III, identifying the internal oxidation as alumina and the TGO as alumina and a predominantly chromia mixed oxide.

A significant number of inclusions can be observed within the lower part of the bond coat of the HVOF PEB treated sample as illustrated in Figure 6, which shows the four inclusions that were analyzed. The results of the analyses are given in Table IV and show that all inclusions are essentially aluminium nitride, with small traces of some of the bond coat constituents. Although these trace inclusions could be due to the analyzing beam penetrating slightly into the bond coat.

The PEB process leads to a re-melted MCrAlY surface layer, resulting in an extremely smooth surface as shown in part 1 [9] and a very fine grained microstructure as shown in Figure 7. During this process yttrium in the coating can oxidise forming a dispersion of yttria in this re-melted layer. Re-solidification leads to a much finer $\beta+\alpha$ microstructure and seals any prior particle boundaries, but may result in the solution of nitrogen from these pores and channels into the coating.

Subsequent oxidation leads to the formation of a protective alumina layer, that appears to be slow growing, together with the internal precipitation of aluminium nitride particles, that grow with cyclic service. However, in the longer term, the maintenance of a protective alumina, thermally grown oxide, which is thin, adherent and does not crack or spall, extends the coating life. 
The parabolic rate constant was calculated for the HVOF and the HVOF PEB treated samples and was found to be $1.3 \times 10^{-16} \mathrm{~m}^{2} \mathrm{~s}^{-1}$ and $3.1 \times 10^{-17} \mathrm{~m}^{2} \mathrm{~s}^{-1}$ respectively, showing that the PEB treatment has a significant effect on the rate of alumina growth. These calculated values for the parabolic rate constant fall within the range expected for alumina forming alloys [13]. Aluminium from the non-PEB HVOF bondcoat is consumed more rapidly by external scale growth as well as internal oxidation leading to breakaway oxidation, the formation of less protective oxides and hence early coating failure, when compared to the PEB treated samples.

\section{Conclusions}

- The PEB treatment significantly improves the life of EB PVD TBCs on HVOF bond coat systems.

- The PEB treatment in HVOF bond coats promotes the formation of a continuous alumina scale suppressing the formation of breakaway oxidation.

- The PEB treatment had no measurable effect on the VPS coatings.

\section{Acknowledgements}

The authors would like to thank the EC for funding the work presented in this paper under the 'Asterixe' Project, No: NMP3-CT-2003-505953. The authors would also like to thank Mr. Tony Gray of Cranfield University for the deposition of the YSZ ceramic top coats onto the samples. 


\section{References}

1. R.A Miller, Surface and Coatings Technology, $\underline{30}$, (1987) 1.

2. F.O Soeching, Thermal Barrier Coatings Workshop NASA Conference Publication 3312 (1995) 1.

3. T.A Cruse, S.E Stewart and M Ortiz, Transactions of the ASME, $\underline{110}$, (1988) 610.

4. B.C Wu, E Chang, S.F Chang and C.H Chao, Thin Solid Films, 172, (1989) 185.

5. J.H Sun, E Chang, B.C Wu and C.H Tsai, Surface and Coatings Technology, 58, (1993) 93.

6. R.G Wellman, M.J Deakin and J.R Nicholls, Wear, 258, (2005) 349.

7. X Chen, M.Y He, I Spitsberg, N.A Fleck, J.W Hutchinson and A.G Evans, Wear, 256, (2004) 735.

8. Y. H. Sohn , J. h. Kim, E. H. Jordan and M. Gell, Surface and Coatings Technology, 146-147, (2001) 70 .

9. A Weisenburger, G Rizzi, A Scrivani, G Mueller and J.R Nicholls, Surface and Coatings Technology,

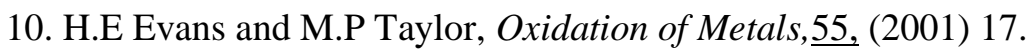

11.E.P Busso, J Lin, S Sakurai and M Nakayama, Acta Materialia,49, (2001) 1515.

12.J.A Haynes, E.D Rigney, M.K Ferber and W. D Porter, Surface and Coatings Technolog, 86-87, (1996) 102.

13.H Hindam and D.P Whittle, Oxidation of Metals, 18, (1983) 245. 
Table 1: Nominal chemical composition of the CoNiCrAlY powders used for all deposition tests.

\begin{tabular}{|l|l|l|l|l|l|}
\hline & Cr & Ni & Al & Y & Co \\
\hline Wt.-\% & 21.0 & 32.0 & 8.0 & 0.5 & Bal. \\
\hline
\end{tabular}


Table II: Results of the testing in cycles to failure at $1500^{\circ} \mathrm{C}$.

\begin{tabular}{|c|c|c|c|}
\hline & Test 1 & Test 2 & Test 3 \\
\hline HVOF & 471 & 215 & 545 \\
\hline HVOF PEB & 921 & 778 & - \\
\hline VPS & 323 & 98 & 170 \\
\hline VPS PEB & 261 & 98 & 213 \\
\hline LPPS & 110 & 102 & 196 \\
\hline PtAl & 210 & 313 & 148 \\
\hline
\end{tabular}


Table III: SEM EDAX elemental analyses of different points on the TGO and bond coat, in atomic percent.

\begin{tabular}{|l|r|r|r|}
\hline & \multicolumn{1}{|l|}{ Pt 1 } & Pt 2 & \multicolumn{1}{l|}{ Pt3 } \\
\hline $\mathrm{O}$ & 62.08 & 63.74 & 63.6 \\
\hline $\mathrm{Al}$ & 8.47 & 36.07 & 36.4 \\
\hline $\mathrm{Cr}$ & 25.96 & 0.19 & \\
\hline $\mathrm{Mn}$ & 2.06 & & \\
\hline $\mathrm{Co}$ & 0.75 & & \\
\hline $\mathrm{Ni}$ & 0.68 & & \\
\hline
\end{tabular}


Table IV: Local analysis on nitrides precipitates in HVOF PEB bond coat.

\begin{tabular}{|l|r|r|r|r|}
\hline & $\begin{array}{l}\text { Spectrum 1 } \\
\text { (at\%) }\end{array}$ & $\begin{array}{l}\text { Spectrum 2 } \\
\text { (at\%) }\end{array}$ & $\begin{array}{l}\text { Spectrum 3 } \\
\text { (at\%) }\end{array}$ & $\begin{array}{l}\text { Spectrum 4 } \\
\text { (at\%) }\end{array}$ \\
\hline $\mathrm{N}$ & 50.71 & 42 & 49.74 & 44.41 \\
\hline $\mathrm{O}$ & & & & 5.32 \\
\hline $\mathrm{Al}$ & 48.29 & 48.19 & 49.31 & 47.22 \\
\hline $\mathrm{Cr}$ & 0.41 & 2.98 & 0.34 & 0.96 \\
\hline $\mathrm{Fe}$ & & 1.37 & 0.22 & 0.46 \\
\hline $\mathrm{Co}$ & 0.19 & 1.51 & & 0.5 \\
\hline $\mathrm{Ni}$ & 0.4 & 3.61 & 0.4 & 1.14 \\
\hline $\mathrm{Mo}$ & & 0.33 & & \\
\hline
\end{tabular}


Figure 1: (a) Micrographs of the as sprayed HVOF bond coat system after cyclic oxidation testing at $1150^{\circ} \mathrm{C}$ (b) Schematic illustrating the evolution of damage during cyclic testing [8]

Figure 2: Micrographs of the HVOF bond coat system with PEB treatment after cyclic oxidation testing at $1500^{\circ} \mathrm{C}$.

Figure 3: Probability plot of oxide thickness for the HVOF and the HVOF PEB samples at $1500^{\circ} \mathrm{C}\left[\mathrm{Note}^{\circ}\right.$ different hot cycle times to failure: 471 cycles for HVOF and 921 cycles for PEB-HVOF sample].

Figure 4: SEM micrograph of the HVOF PEB bond coat showing the continuous alumina scale and a region of breakaway oxidation, consisting of $\mathrm{Cr} / \mathrm{Ni}$ spinells.

Figure 5: SEM micrograph of the TGO and the bondcoat of the HVOF sample showing the areas where point analyses were conducted.

Figure 6: Local analysis on nitrides precipitates in HVOF PEB bond coat.

Figure 7: SEM micrograph of the top view of the PEB treated HVOF bond coat showing the small grain size of the recrystallised PEB treated surface. 


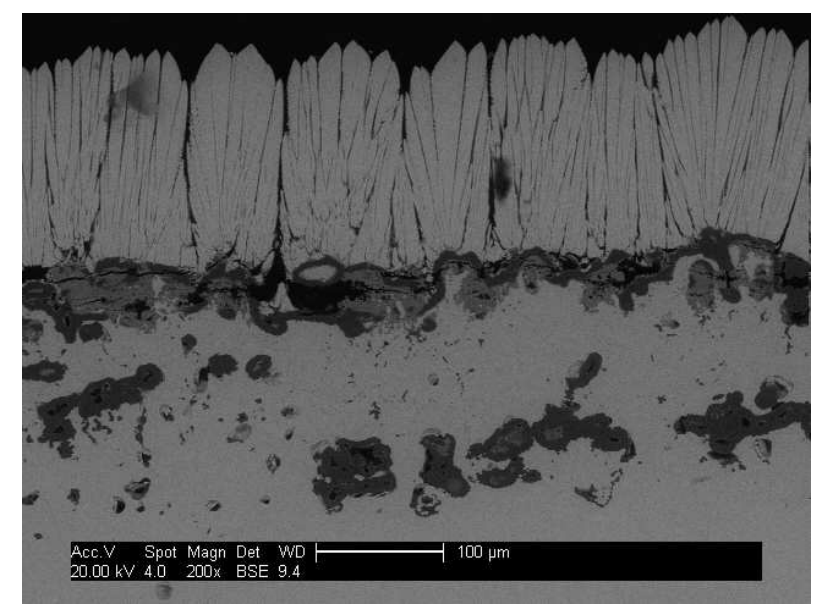

(a)

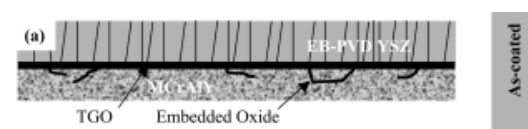

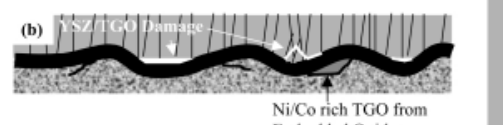

(e)

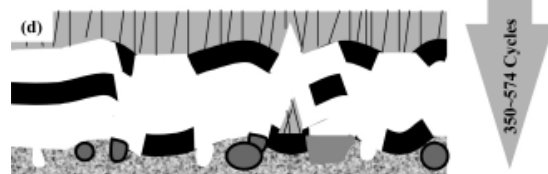

(b)

Fig 1 


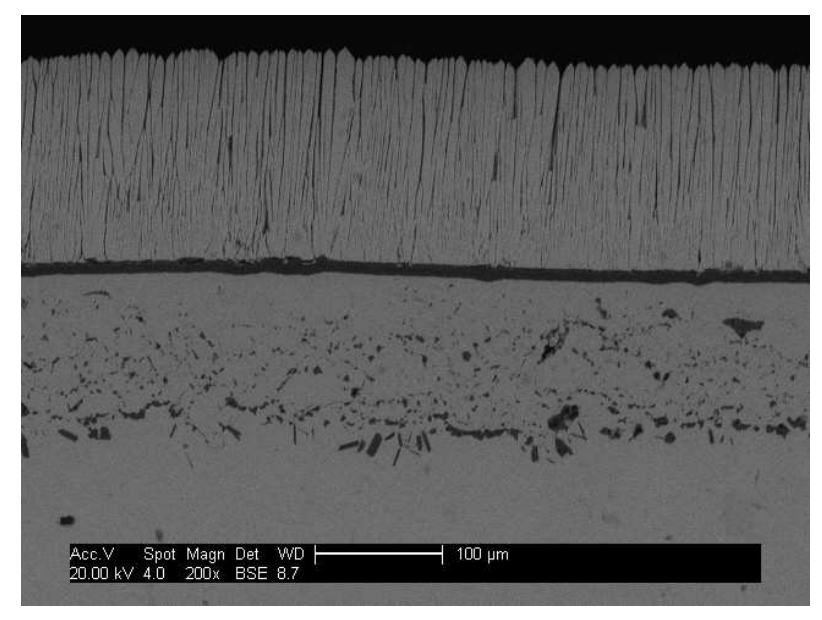

Fig 2 


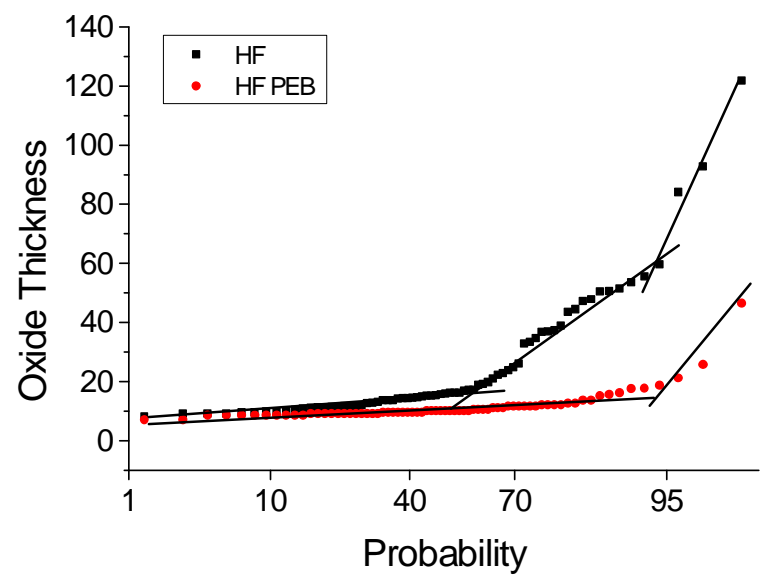

Fig 3 


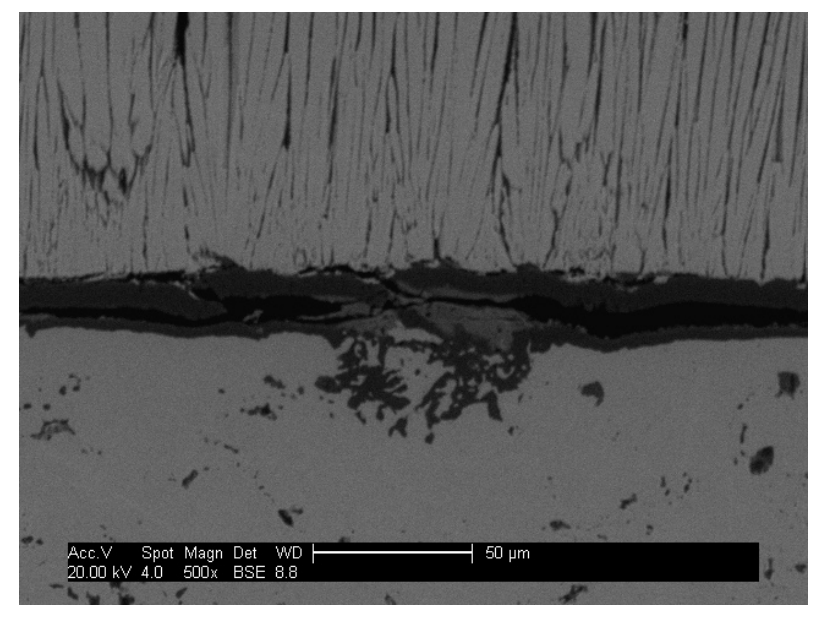

Fig 4 


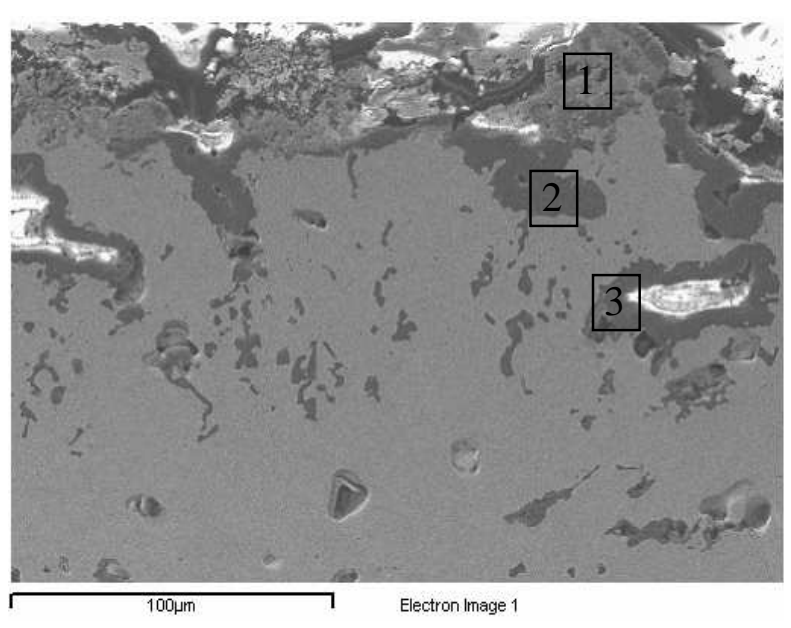

Fig 5 


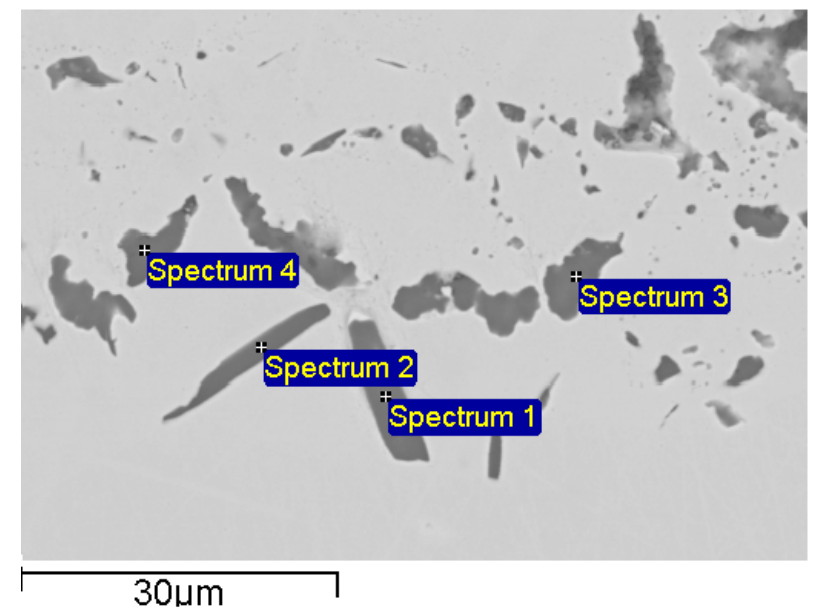

Fig 6 


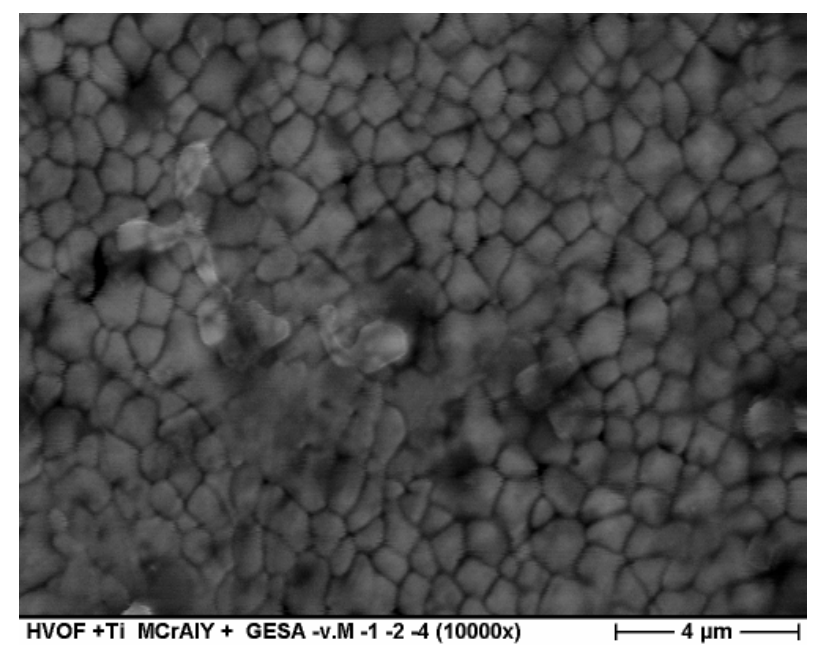

Fig 7 